\title{
Precursor motion to iceberg calving at Jakobshavn Isbræ, Greenland, observed with terrestrial radar interferometry
}

\author{
SURUI XIE, ${ }^{1}$ TIMOTHY H. DIXON, ${ }^{1}$ DENIS VOYTENKO, ${ }^{2}$ DAVID M. HOLLAND, ${ }^{2,3}$ \\ DENISE HOLLAND, ${ }^{2,3}$ TIANTIAN ZHENG ${ }^{3}$
}

\author{
${ }^{1}$ School of Geosciences, University of South Florida, Tampa, FL, USA \\ ${ }^{2}$ Courant Institute of Mathematical Sciences, New York University, New York, NY, USA \\ ${ }^{3}$ Center for Global Sea Level Change, New York University, Abu Dhabi, UAE \\ Correspondence: Surui Xie <suruixie@mail.usf.edu>
}

\begin{abstract}
Time-varying elevations near the calving front of Jakobshavn Isbræ, Greenland were observed with a terrestrial radar interferometer (TRI) in June 2015. An ice block with surface dimensions of $1370 \mathrm{~m} \times 290 \mathrm{~m}$ calved on 10 June. TRI-generated time series show that ice elevation near the calving front began to increase $65 \mathrm{~h}$ prior to the event, and can be fit with a simple block rotation model. We hypothesize that subsurface melting at the base of the floating terminus breaks the gravity-buoyancy equilibrium, leading to slow subsidence and rotation of the block, and its eventual failure.
\end{abstract}

KEYWORDS: glacier calving, ice block rotation, Lagrangian coordinates, subsurface melting, terrestrial radar interferometry

\section{INTRODUCTION}

Jakobshavn Isbræ, Greenland's largest marine-terminating glacier, has doubled in speed as its ice front has retreated tens of $\mathrm{km}$ in the last several decades (Joughin and others, 2004, 2008; Rignot and Kanagaratnam, 2006; Howat and others, 2011). Increases in subsurface melting and calving triggered by warmer ocean water are believed to be important contributors to this process (Holland and others, 2008; Motyka and others, 2011; Enderlin and Howat, 2013; Myers and Ribergaard, 2013; Truffer and Motyka, 2016).

Modeling the calving process is challenging, and has produced conflicting results. A finite-element model of stress evolution near the front of marine-terminating glaciers suggests that undercutting of the ice front due to frontal melting near the base is a strong driver of calving ( $\mathrm{O}^{\prime}$ Leary and Christoffersen, 2013). However, a vertical 2-D ice flow model found that crevasse water depth and basal water pressure could have significant effects, while submarine melt undercutting and backstress from ice mélange are less important (Cook and others, 2014). The models of Cook and others (2014) and many others (e.g., Nick and others (model CDw), 2010; Otero and others, 2010), use the calving criterion of Benn and others (2007), which assumes that calving happens when the depth of surface crevasses reaches the waterline, and does not require a basal crevassing condition. Recent work by Murray and others (2015a, b) cast doubt on this calving criterion. Their data show that the front of Helheim Glacier tipped backwards during a major calving event, which implies that basal crevassing must be considered in calving criteria at least under certain conditions. Detailed observations of ice geometry and kinematics near the calving front can provide constraints on calving models. Amundson and others (2010) used timelapse imagery, GPS, ocean pressure and seismic observations at Jakobshavn Isbræ to demonstrate that sea ice coverage and the strength of mélange affect the seasonal variations in calving rate and terminus stability: the glacier terminus advances in winter when the dense and strong ice mélange prevents calving, and retreats in summer when the ice mélange becomes weak. A simple force-balance analysis suggested that when there is a resistive ice mélange, bottom-out rotation of the calving block is strongly preferred over top-out rotation. By using photogrammetric time-lapse imagery, Rosenau and others (2013) documented a major calving event at Jakobshavn Isbræ, finding large vertical displacements of the glacier front of order $15 \mathrm{~m}$ and lowering of order $8 \mathrm{~m}$ at a position $500 \mathrm{~m}$ from the calving front $2 \mathrm{~d}$ before the calving event, similar to the observations at Helheim Glacier by Murray and others $(2015 a, b)$.

Terrestrial radar interferometry (TRI) allows detailed observations of the calving front, generating high-resolution elevation and velocity data with short (several minutes or less) repeat intervals (Dixon and others, 2012; Peters and others, 2015; Voytenko and others, 2015a, b, c). With this instrument, we can measure glacier motion and map ice velocity and elevation over a wide area, overcoming the limitations of GPS (low spatial resolution, difficult to deploy near the calving front), photogrammetry (low reliability in bad weather and at night), and satellite observations (low temporal resolution). Using continuous TRI observations near the terminus of Jakobshavn Isbræ acquired for $4 \mathrm{~d}$ in June 2015, we discuss the possible role of crevasses and basal melting before and during a calving event.

\section{DATA ACQUISITION}

We observed the terminus of Jakobshavn Isbræ with a TRI from June 6-10 2015. The instrument is a real-aperture radar operating at Ku-band $(1.74 \mathrm{~cm}$ wavelength) and is sensitive to line-of-sight (LOS) displacements of $\sim 1 \mathrm{~mm}$ (Werner and others, 2008). The instrument was mounted on a metal pedestal on solid rock $\sim 3 \mathrm{~km}$ away from the calving front, and protected by a radome to eliminate disturbance from wind and rain (Fig. 1). Figure 2 shows the area measured during $4 \mathrm{~d}$ of continuous observation. The TRI scanned a $150^{\circ}$ arc at a sampling rate of $90 \mathrm{~s}$, generating images with both phase and 


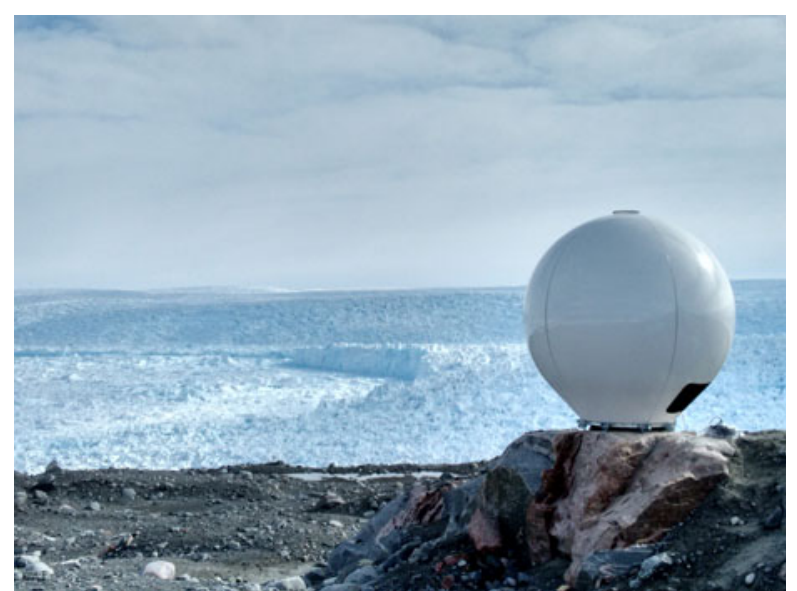

Fig. 1. TRI set-up at Jakobshavn Isbræ, Greenland. The instrument is inside the radome, the height of the radome is $\sim 3 \mathrm{~m}$. The calving front is $\sim 3 \mathrm{~km}$ away.

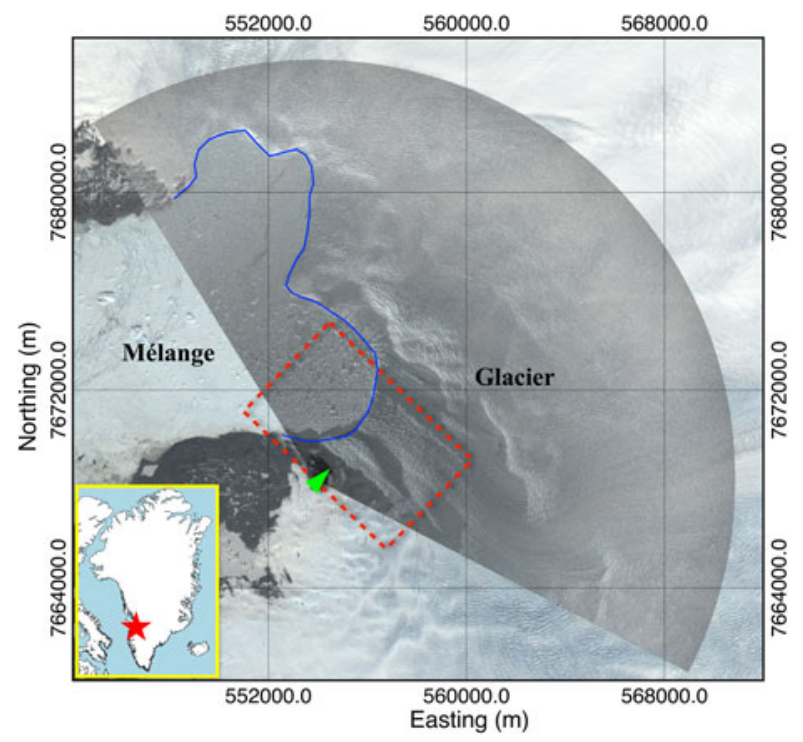

Fig. 2. TRI intensity image of the study area overlain on a Landsat-8 image (4 June 2015). The radar scanned a $150^{\circ}$ arc. Blue line indicates the ice cliff, green triangle shows the location of the radar, dashed red rectangle outlines the area shown in Figures 3, $4 \mathrm{a}, 5 \mathrm{a}$. The coordinates are in UTM zone $22 \mathrm{~N}$. intensity information. The resolution of the range measurements is $\sim 1 \mathrm{~m}$. The azimuth resolution varies linearly with distance: for example, $7 \mathrm{~m}$ at $2 \mathrm{~km}$ distance, $14 \mathrm{~m}$ at $4 \mathrm{~km}$.

The TRI has one transmitting antenna and two receiving antennas, which allow for repeat topographic mapping of fast moving glaciers (Strozzi and others, 2012; Voytenko and others, 2015a). The baseline length (vertical offset between the two receiving antennas) in this campaign was $60 \mathrm{~cm}$.

\section{DATA ANALYSIS AND RESULTS}

We first converted unwrapped phases into elevation maps using a geodetic reference height on the stationary rock, then adjusted the elevation into a local height coordinate system relative to the mean water level in the fjord. The results were resampled into $10 \mathrm{~m}$ pixel spacing maps and georeferenced into UTM coordinates for further analysis.

The TRI captured several small calving events during its 4-d observation period, and one large calving event near the end. Here we focus on the large calving event. Figure 3 shows the intensity images before (a) and after (b) this event. Surface dimensions of the calved block are $\sim 1370 \mathrm{~m} \times 290 \mathrm{~m}$.

For fast moving glaciers like Jakobshavn Isbræ, ice near the terminus can move over $30 \mathrm{~m} \mathrm{~d}^{-1}$, so the location of the calving front can change more than $120 \mathrm{~m}$ during $4 \mathrm{~d}$ of observation. This motion must be considered when analyzing elevation variations of the glacier front. Our radar data are acquired in a fixed Cartesian system, so a given ice particle at the surface of the glacier travels through this Cartesian coordinate system (Eulerian reference frame). For this study, it is also useful to consider a Lagrangian reference frame, where we track a given particle of ice through time. We converted our elevation time series, originally defined in an Eulerian frame, into a Lagrangian frame, as follows:

$$
H_{\text {Lag }}\left(x_{\text {Lag }}, y_{\text {Lag }}\right)_{\mathrm{t}}=H_{\text {Eul }}\left(x_{0}+\mathrm{d} x, y_{0}+\mathrm{d} y\right)_{\mathrm{t}}
$$

where $H_{\text {Lag }}$ and $H_{\text {Eul }}$ are elevations in the Lagrangian and Eulerian frame, respectively; $\left(x_{\text {Lag, }} y_{\text {Lag }}\right)$ are the coordinates in the Lagrangian system, set equal to the initial coordinates $\left(x_{0}, y_{0}\right)$ at $t_{0}$ in the Eulerian frame; and $d x$ and $d y$ are the horizontal displacements (relative to $t_{0}$ ) of ice at time $t$ in the Eulerian frame.

To obtain $d x$ and $d y$ in Eqn (1), we estimated ice motion by using the feature tracking method in OpenCV (http://opencv. org/). Figure 4 is an example of ice motion derived by
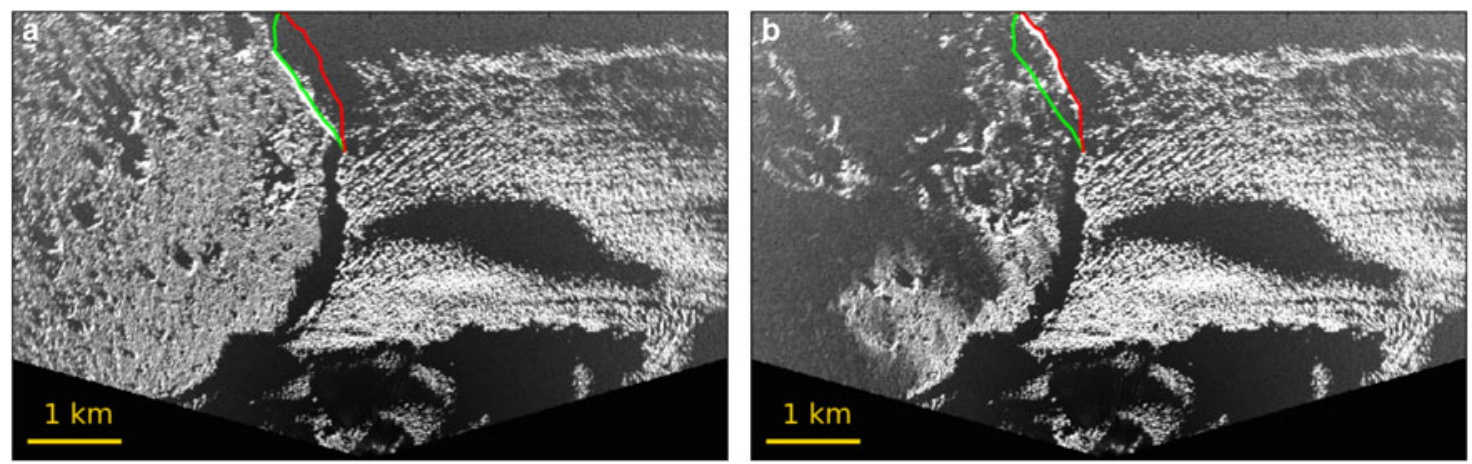

Fig. 3. TRI images before (a) and after (b) calving on 10 June 2015, for the area outlined by a red box in Figure 2. Green line indicates the ice cliff before calving, red line after calving. Image b was obtained 26 min after image a. Black areas are in radar shadow. 


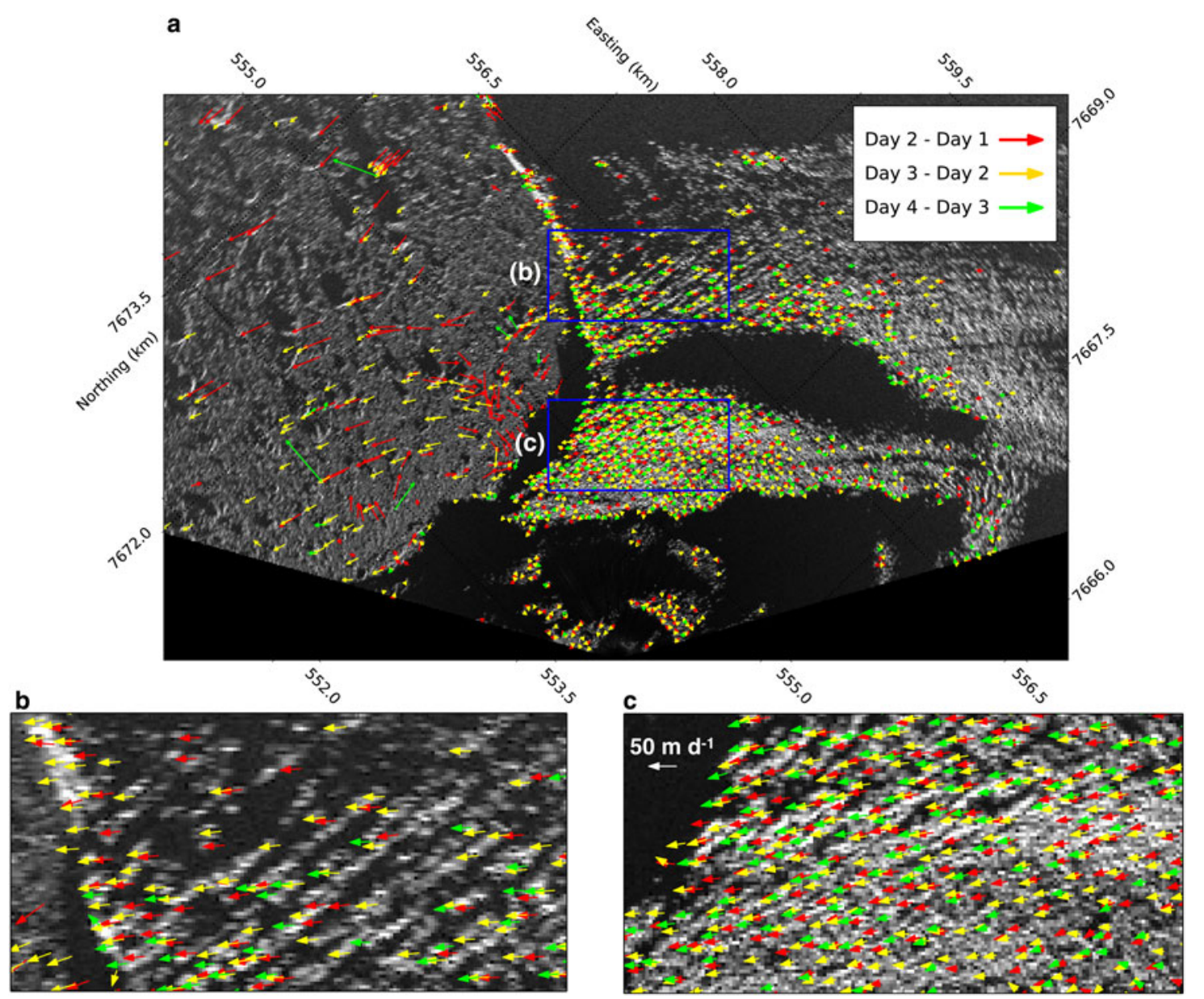

Fig. 4. Daily ice velocity estimated by tracking motion of distinct features. Blue boxes in (a) outline areas shown in more detail in (b), (c). Length of arrows is on the same scale as the background TRI intensity images (they are in the same reference coordinate system, 1 pixel length $=10 \mathrm{~m}$ ). Black areas are in radar shadow.

tracking distinct features such as the edges of surface crevasses on TRI intensity images. The velocity of the ice mélange is quite variable since even small calving events can cause large mélange motion. The glacier motion is variable over hourly timescales, but is relatively consistent over longer (1 d) periods. The estimated speed near the calving front was $\sim 34 \mathrm{~m} \mathrm{~d}^{-1}$ during our observations.

Topographic mapping with the TRI is based on the interferometric imaging geometries of the two receiving antennas and the various targets in the imaged swath (Strozzi and others, 2012). Two steps are necessary to convert unwrapped phases into elevation maps. First, we need to estimate the 'expected' phase at the radar position based on the elevation difference between the instrument and the reference point. Second, an elevation map is derived from the phase difference between the 'expected' radar phase and the unwrapped phase map. Ideally, for the first step, if we choose a stationary point (e.g., rock) as the reference elevation point, the 'expected' phases of the radar at different times should be the same. In reality, however, the phase of the radar position estimated at different times can be slightly different because of measurement noise. Since we hope to exploit the timevarying DEM capability of our TRI instrument, we cannot rely on long time (hour-scale) averages of multiple DEMs to reduce random noise in the elevation estimates. This noise is mainly due to atmospheric propagation effects (especially from variable water vapour) and possible small variations in antenna orientation associated with the scanning motion of the radar (the radome eliminates antenna motion due to wind).

We corrected the elevation estimates in two stages. As described above, a first order correction is applied by subtracting the 'expected' phase differences from a stationary point on rock $\sim 600 \mathrm{~m}$ away from the instrument. This corrects the majority of effects due to antenna wobble, but may not improve the elevation estimates in the areas of interest on the glacier, as these are farther from the radar, and the radar signal propagates through atmosphere that is spatially and temporally variable. In a second step, we use elevation estimates in the mélange immediately in front of the glacier (box $b$ in Fig. 5a) to correct the DEM on the glacier near the calving front, since we expect noise sources in the two areas to be similar. Tidal signals in the mélange are of order $1 \mathrm{~m}$ in amplitude, below the noise level of the elevation estimates, and we assume that over the $4 \mathrm{~d}$ of observation, the mean elevation change in this area is close to zero (no large icebergs entered the area during this period until the studied calving event). The resulting RMS scatter in the mélange (box b) is $1.8 \mathrm{~m}$ (Fig. 5b), about the level expected given instrument noise, atmospheric effects and tides. The elevations on the nearby glacier change by amounts that are much larger, but have several 'tears' in the time series associated with phase breaks. The deviations from the mean height in the mélange are used to correct these phase 


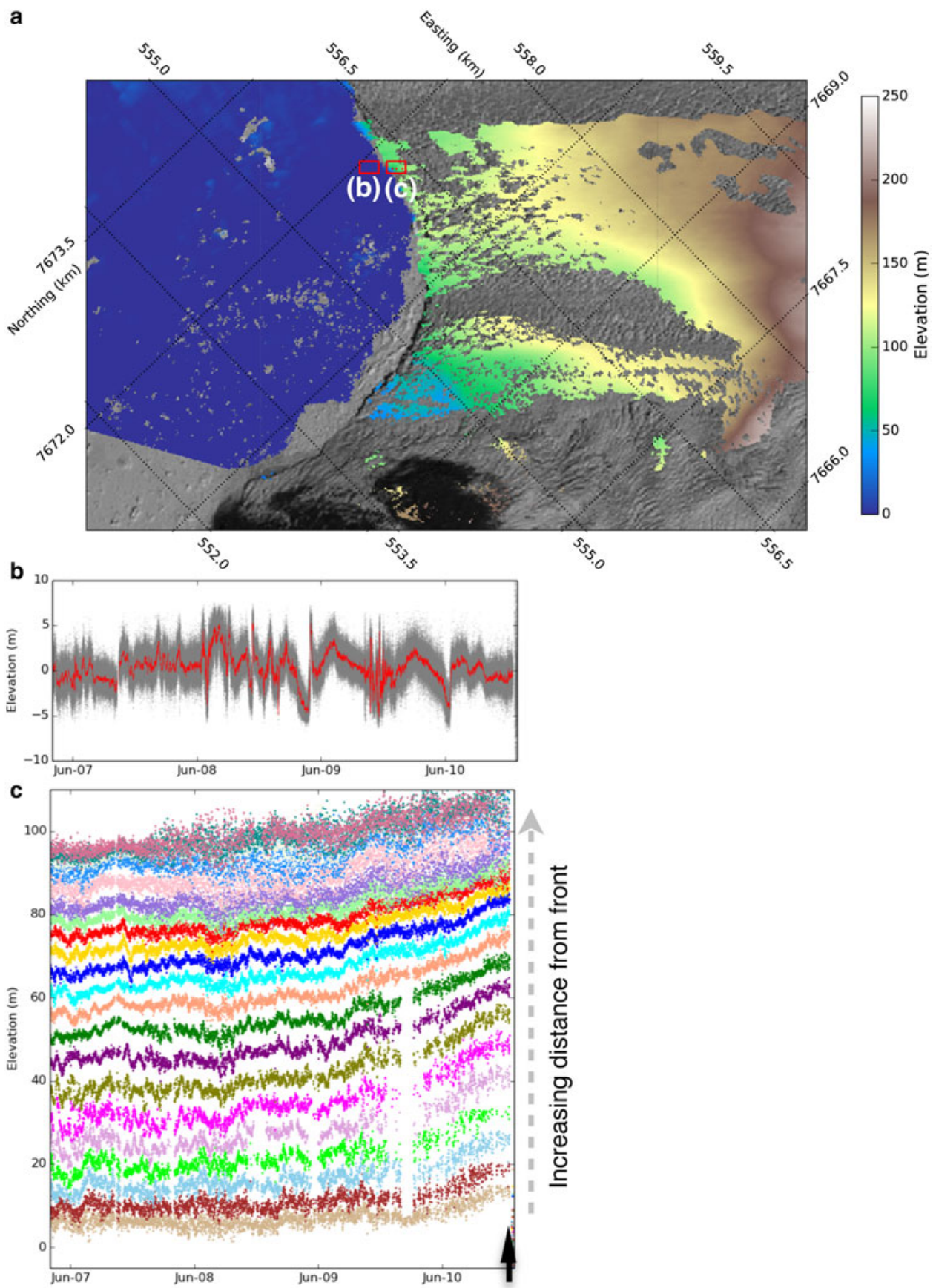

Fig. 5. (a), Averaged elevation map overlain on a Landsat-8 image, red rectangles indicate areas with more detailed elevation data $(b=$ mélange in (b); $c=$ ice front in (c)). (b) Stacked elevation time series for mélange, grey dots represent elevation values for all pixels $(10 \mathrm{~m} \times 10 \mathrm{~m}$ size) within box b; red line shows mean elevation. Note that the mean is close to zero; RMS variation represents combined effects of tides, atmosphere delay and phase unwrapping errors. (c) Time-varying elevation for different points along a flow line in box c, arranged in order of increasing distance from front. Black arrow indicates time of large calving event on 10 June 2015.

breaks. The corrected elevations still exhibit changes across the glacier front that are up to an order of magnitude higher than the changes in mélange (Fig. 5c).

Figure $5 \mathrm{a}$ is an averaged elevation map overlain on a Landsat- 8 image. Figure $5 \mathrm{c}$ shows the corrected elevation profiles of points separated by $10 \mathrm{~m}$ along an approximate flow line beginning near the cliff that calved during the main calving event. The black arrow indicates the time of calving on 10 June 2015 . In the $4 \mathrm{~d}$ before the large calving event the elevation of the glacier front increased by up to $20 \mathrm{~m}$, in a way that is consistent with a simple block rotation model, as described below. These results are similar to the findings of Murray and others (2015a) who studied
Helheim Glacier with GPS and photogrammetry. They suggested that glaciers can calve by a process of buoyancyinduced crevassing, with ice down-glacier in zones of flexure rotating upward (bottom-out rotation) because of disequilibrium.

The pattern of elevation increases along a flow line close to the ice cliff can be explained as follows. Assuming block behaviour, as the frontal ice block begins to flex at the beginning of a calving event, elevations near the cliff initially increase and the basal crevasse evolves and widens. Once the ice block is significantly out of equilibrium, ice failure can happen rapidly. The ice flexure and crevasse growth are separate physical processes that can be mutually 
reinforcing. We simplified these processes with a model of a single rigid block undergoing rotation with no internal deformation. Figure 6 is a cartoon showing the process. The new TRI data allow us to describe the timing and geometry of this process in some detail.

The surface width of the ice block, $W$, can be determined directly from the TRI intensity images before and after the calving event. On a cross section plane, for a point on the upper surface with initial distance of $d_{0}$ to the ice cliff, and initial elevation of $h_{0}$, the horizontal distance from this point to the cliff is:

$$
d=W-\left[\left(W-d_{0}\right) \cos \theta-\left(h_{0}-H_{0}\right) \sin \theta\right]
$$

where $H_{0}$ is the initial height of the intersection axis (the top of the calving surface of Fig. 6a) and $\theta$ is the rotation angle. The expression for elevation is:

$$
h=\left(W-d_{0}\right) \sin \theta+\left(h_{0}-H_{0}\right) \cos \theta+H_{0}-D
$$

where $D$ is the downward motion of the ice block (Fig. 6). Equations (2) and (3) assume the ice block rotates about the intersection axis in a rigid way.

To test this model, we selected a profile along a line that is perpendicular to the calving surface (the angle between the profile and the flow line direction is $\sim 33^{\circ}$ ), and estimated elevations along the profile at different times (Fig. 7). Our time-varying DEMs effectively represent $15 \mathrm{~min}$ time averages, and are generated as follows: For each time increment, we derive elevations from five scans on each side (total of ten scans, spanning $15 \mathrm{~min}$ ) and take the median value. If there are no usable measurements within a given 15 min increment, then there are no elevation estimates for that time. For comparison, different colour-coded curves in Figure 7 show the best-fit estimates for a rigidly rotating ice block, allowing the block edge on the upstream side to shift downward on the new ice cliff as calving proceeds. Figure 8 plots the rotation angle as a function of time (Supplementary Fig. S1 plots the downward motion as a function of time). Note the sudden drop at $\sim 28.5 \mathrm{~h}$ before the calving event, which coincides with the time that a small piece of ice on the edge of the calving block fell from the cliff (Fig. 9).

Rosenau and others (2013) used time-lapse photography to suggest that vertical displacements of the glacier front at Jakobshavn Isbræ began $\sim 2 \mathrm{~d}$ before a calving event. From Figure 7 and 8 , we conclude that the calving process for our studied event actually started at least $65 \mathrm{~h}$ prior to the visually observed calving event.

\section{DISCUSSION}

Our simple block rotation model describes glacier front motion several days prior to a major calving event. The model has just three parameters: block width $(W)$, rotation angle $(\theta)$ and downward motion of the up-glacier edge of the block $(D) . W$ is determined directly from the intensity images, while $\theta$ and $D$ are determined by fitting the elevation time series data with model predictions. Figures 7, 8 show that the ice block started rotating at least $65 \mathrm{~h}$ before the calving event, a clear strain precursor to subsequent ice failure. The cross-over points in Figure 7 define an approximate lower bound for the width of the future calved block. Figure 7 also suggests that the elevation of ice close to the rotation axis decreases during the later stages of the calving process. The TRI intensity images support this: the observable ice surface becomes narrower as the up-glacier ice subsides and is shadowed by the higher down-glacier ice (Supplementary Fig. S2).
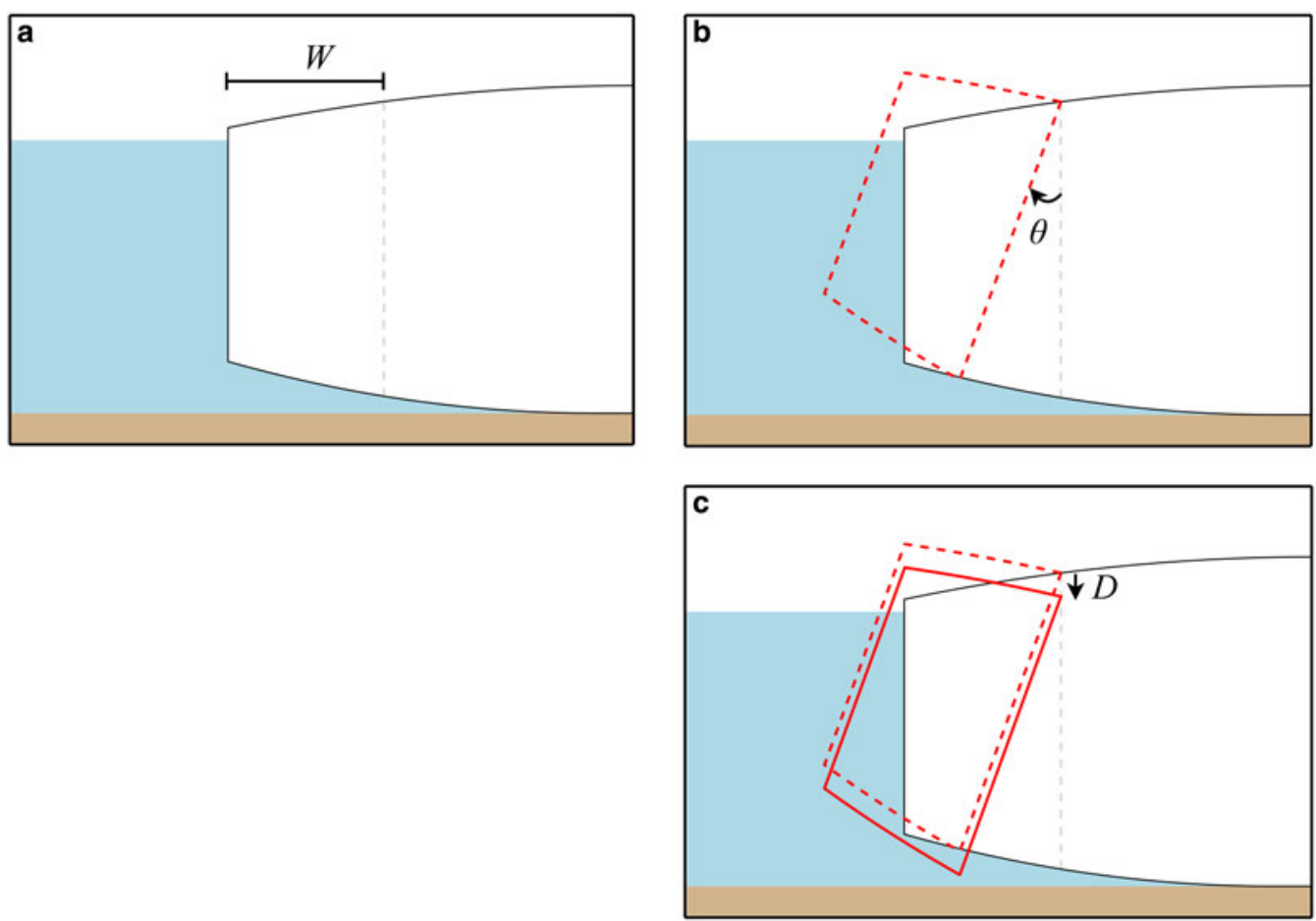

Fig. 6. Cartoon of simplified rigid block rotation model, showing how elevation temporarily increases at the glacier front and defining the three variables. (a) Initial state, showing block width $W$. Dashed line marks the breaking surface during calving. (b) Dashed red shape shows how the calving block rotates by angle $\theta$. (c) Solid red shape shows that the calving block also slides downward by distance $D$, while rotating about a horizontal axis. 


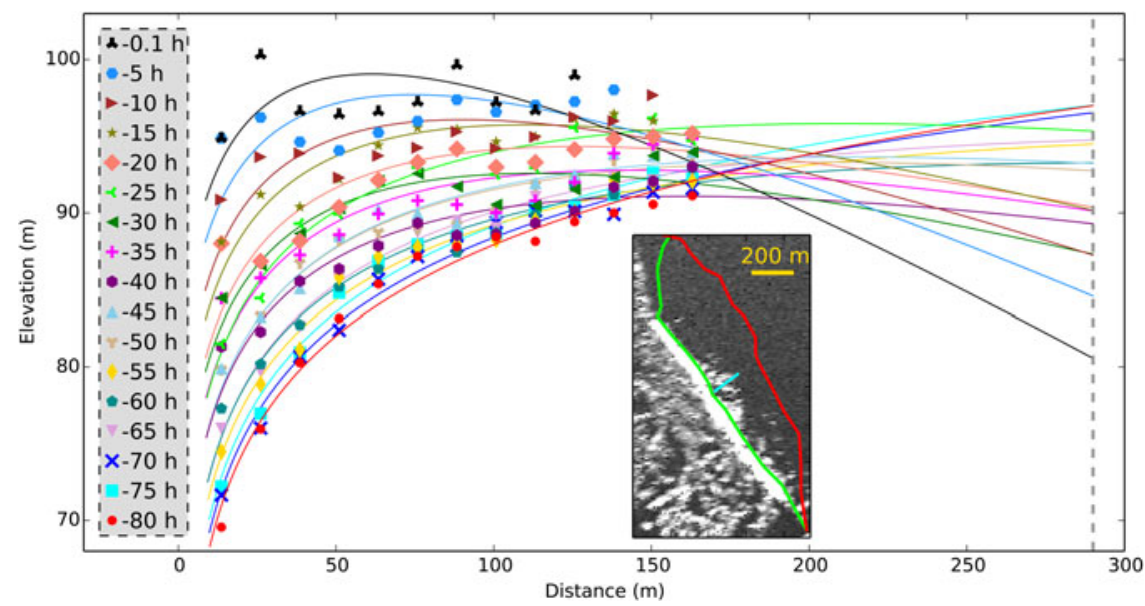

Fig. 7. Elevation profiles on the calving ice block at different times (hours before the calving event). Profiles are taken along the cyan line on the inserted TRI image, which is perpendicular to the calving front (green line on the TRI image). Distance is from the point to the ice cliff before the calving event, vertical dashed grey line (right hand side) marks the distance of the cliff after the calving event (red line on the TRI images). Markers show observed elevations on different times. Red curve is the best fit of a logarithmic function to the elevation profile at $-80 \mathrm{~h}$. Other colour-coded curves are the best-fit profiles at different times obtained by rotating the red curve about the intersection point on the dashed grey line and shifting it up or down to fit the observed elevations. Up-glacier side was shadowed by the higher down-glacier side so it is not possible to measure the surface subsidence here with this LOS radar.

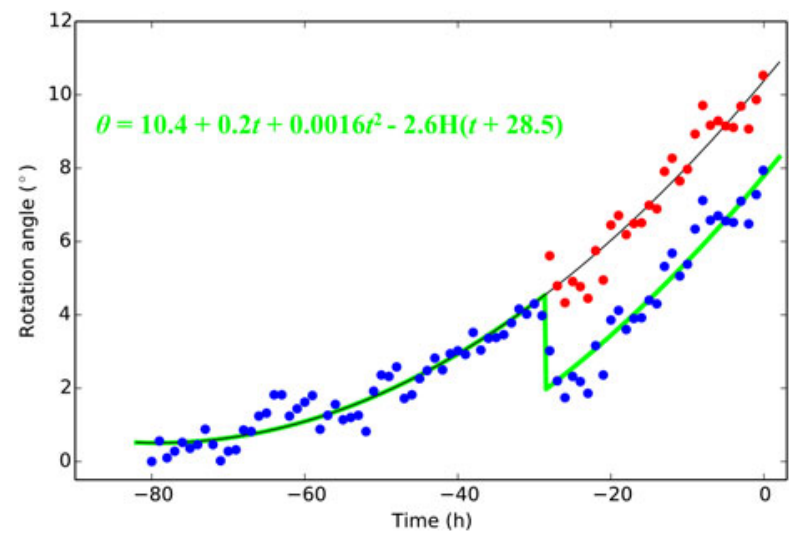

Fig. 8. Ice block rotation angle versus time. Blue dots are rotation angle estimates; red dots are rotation angles corrected by adding a Heaviside $(\mathrm{H})$ step function after an ice failure event $\sim 28.5 \mathrm{~h}$ before the main calving event (equation, upper left). Green and black curves are the best fits to the rotation time series before and after correction, assuming simple parabolic behaviour. Supplementary Fig. S1 shows downward motion versus time.

\subsection{The role of subsurface melting}

By studying tidal responses with photogrammetric time-lapse images, Rosenau and others (2013) found a narrow floating zone near the frontal cliff of Jakobshavn Isbræ. Our TRIderived ice velocity estimates and phase lags relative to ocean tides suggest a $\sim 1 \mathrm{~km}$ wide floating zone near the terminus during the observation period (Supplementary Information). The studied calving event happened at the front of this zone. Ice in the floating zone experiences tidal flexing, which can initiate Mode 1 (opening) cracks. These can form as both surface and basal crevasses. While surface crevasses can grow rapidly during a summer, basal crevasses can probably grow more rapidly if warm water is circulating in the fjord, reflecting the higher heat capacity of water relative to air.

Luckman and others (2015) suggest that glacier undercutting driven by warm ocean temperature is an important process that contributes to calving in marine-terminating glaciers. We hypothesize that at the floating zone, where subsurface melting is likely faster than surface melting, the ice block moves out of gravitational equilibrium, which flexes the ice in a narrow zone (within which the new calving
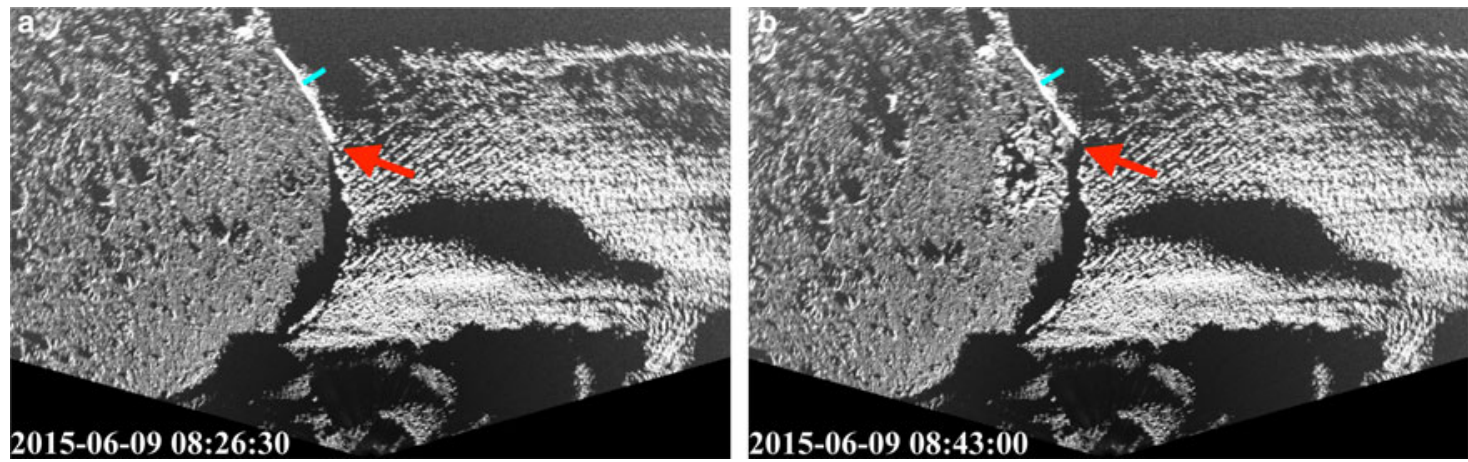

Fig. 9. A small piece of ice on the cliff fell down $\sim 28.5 \mathrm{~h}$ before the major calving event. (a) and (b) are TRI intensity images before and after this minor event. Red arrows indicate the location of ice fall. Note new ice blocks in the mélange and new cliff. Cyan lines show the profile of the ice block analyzed in this study. Time is in UTC. 

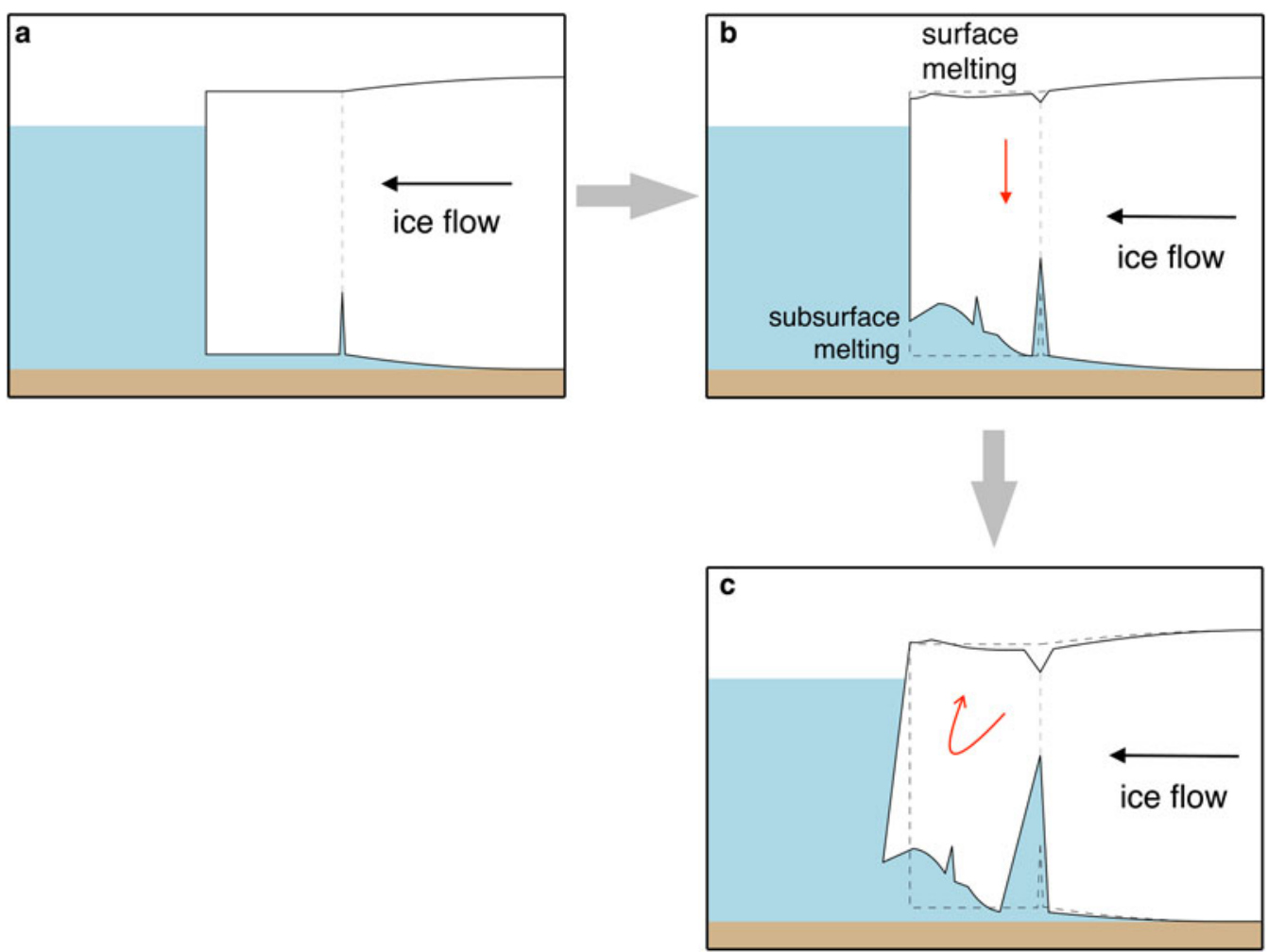

Fig. 10. Sequential sketches of the physical process for calving. (a) Ice near calving front is neutrally buoyant. (b) Submarine melting exceeds surface melting, hence the ice block is no longer gravitationally stable. (c) Ice block sinks and rotates, basal crevasse enlarges, and the block eventually calves.

front will eventually form). As ice in this narrow zone flexes and the block rotates, crevasses enlarge, deforming zones narrow and strain increases exponentially. Eventually a failure threshold is reached and the block collapses. Figure 10 sketches the process. This model also explains the step change in elevation and rotation angle $\sim 28.5 \mathrm{~h}$ before the calving event (Fig. 8): the preliminary ice fall removed mass above the water line, allowing the block to temporarily rebound. Continued subsurface melting eventually allowed the process to continue.

We can test this hypothesis by considering the differential stress generated by plausible amounts of subsurface melting, and comparing with laboratory-measured strength of ice. This analysis (see Supplementary Information) suggests that losses of order $30 \%$ are required to generate buoyancyrelated differential stresses sufficient to initiate failure. This seems high, although ice in the terminal zone may be significantly weaker than laboratory-derived values, depending on the depth of pre-event crevassing. Perhaps a combination of surface and basal crevassing is necessary.

\subsection{Ice failure model}

Voight (1988) described a method for predicting material failure in rocks, soil and other solids under stress:

$$
\dot{\Omega}^{-\alpha} \ddot{\Omega}=A
$$

where $A$ and $\alpha$ are empirical constants, $\Omega$ is an observable quantity related to deformation, and one and two dots refer to the first and second derivatives with respect to time. We suggest this model can also be applied to calving ice. We applied the model to the rotation of the ice block at Jakobshavn Isbræ, with $\Omega$ taken as the rotation angle $\theta$, and the rotation rate $\dot{\theta}$ assumed to be infinite at the time of calving. By using a grid search approach, $A$ and $\alpha$ were estimated to be 23.4 and 4.5. Following Voight (1988), the expression for rotation rate when $\alpha>1$ is:

$$
\dot{\theta}=\left[A(\alpha-1)\left(t_{\mathrm{f}}-t\right)+\dot{\theta}_{\mathrm{f}}^{1-\alpha}\right]^{1 /(1-\alpha)}
$$

where subscript $f$ indicates the time of failure. Figure 11 shows the block rotation rate versus time. The weighted

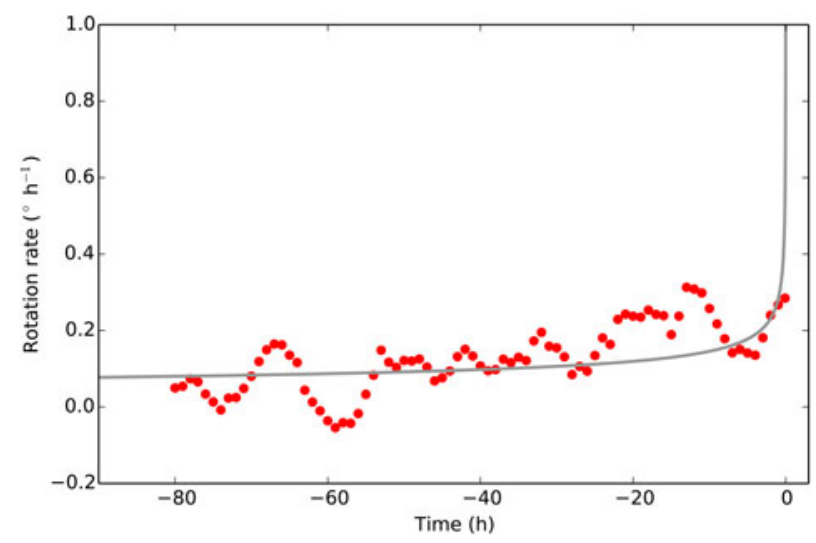

Fig. 11. Ice block rotation rate (red dots) versus time. At time 0 the iceberg collapses and we assume the rotation rate is infinite. Grey curve is the best fit of ice failure model with $A$ and $\alpha$ equal to 23.4 and 4.5, respectively. WRMS residual of model fit is $0.07^{\circ} \mathrm{h}^{-1}$; weights of rates are based on misfits of the rotation model shown in Figure 7. Rotation rate estimates are based on rotation angles shown in Figure 8, using a least-squares smoothing filter (Gorry, 1990), with smoothing window $=5$ and local polynomial approximation of order $=2$. Note that the model fits both the rotation rate data as well as the calving time data. 


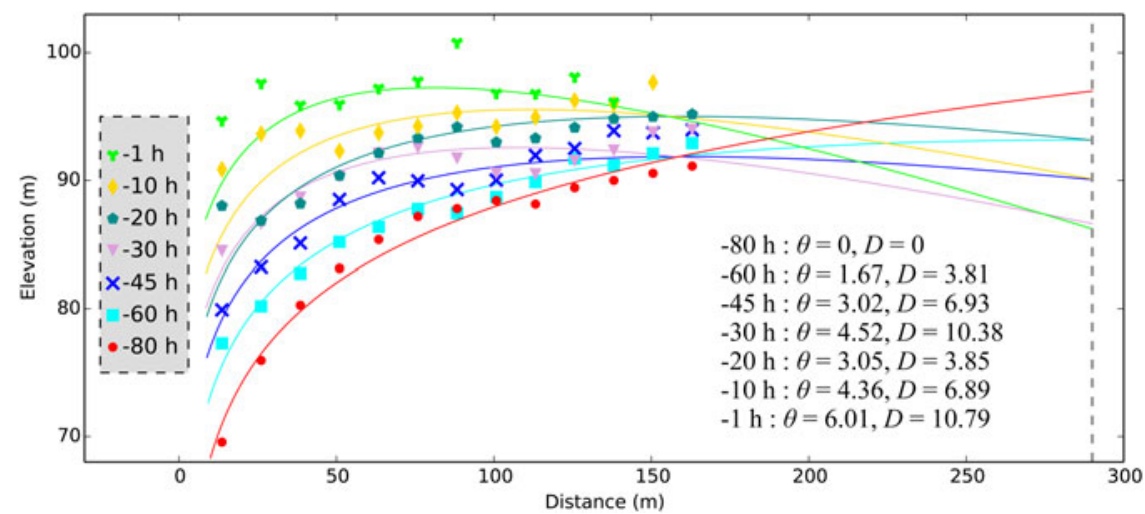

Fig. 12. Elevations from model predictions and TRI observations at different times (hours before the calving event). Distance is from the point to the ice cliff before the calving event, vertical dashed grey line (right hand side) marks the distance to the new ice cliff. Red curve is the best fit of a logarithmic function to the elevation profile at $-80 \mathrm{~h}$; other curves are elevation estimates based on the model. Markers show observed elevations at different times. The rotation angles $\theta$ (in degrees) and downward displacements $D$ (in meters) from the model at different times are shown on the lower right.

root mean square (WRMS, where weights of rates are based on misfits to the rotation model) of the residuals between observations and model predictions, is $0.07^{\circ} \mathrm{h}^{-1}$. With the estimates of $A$ and $\alpha$, the observed quantity (rotation angle or downward motion) can be expressed as (Voight, 1988):

$$
\begin{aligned}
\theta=\frac{1}{A(\alpha-2)}\{[ & \left.A(\alpha-1)\left(t_{\mathrm{f}}-t_{0}\right)+\dot{\theta}_{\mathrm{f}}^{1-\alpha}\right]^{2-\alpha / 1-\alpha} \\
& \left.-\left[A(\alpha-1)\left(t_{\mathrm{f}}-t\right)+\dot{\theta}_{\mathrm{f}}^{1-\alpha}\right]^{2-\alpha / 1-\alpha}\right\}
\end{aligned}
$$

We add a Heaviside step function to account for the small ice failure event $\sim 28.5 \mathrm{~h}$ before the main calving event. For downward motion, the values of $A$ and $\alpha$ are estimated to be 1.1 and 4.3. Based on these estimates and the model, we can derive the elevations of selected points at time $t$ before the calving event. Figure 12 is a plot of TRIderived elevations and predictions based on the ice failure and block rotation models. The rotation angles and downward motions are computed by Eqn (6), assuming $t_{0}=-80 \mathrm{~h}$. The profile locations and elevations are computed from Eqns (2) and (3).

The ice failure model parameters are sensitive to observations immediately before the calving event. Due to limited data quality, the uncertainties of the model predictions are relatively high. Note that the model ignores tidal forcing and assumes no internal deformation in the calving block. Analysis of tidal variations in the fjord shows no evidence that block rotation or ice failure are sensitive to tide or tide rate, but tidal flexing of the ice in the floating zone could extend the depth of crevasses and fracture and weaken the ice (see Supplementary Information). Improved precision in the time-varying elevation estimates, better estimates of local tides, and detailed block shape variations should allow for a better understanding of ice flexure during calving.

\section{CONCLUSIONS}

We used TRI-derived digital elevation models to investigate the behaviour of the calving front at Jakobshavn Isbræ. Ice elevation near the cliff began to increase several days before a major calving event on 10 June 2015. A simple rigid block rotation model matches the elevation profiles and suggests that block capsizing started $\sim 65 \mathrm{~h}$ prior to calving. Subsurface melting in excess of surface melting may over-weight the above-water mass of ice and enhance crevasses, leading to ice deformation, block rotation and eventual ice failure. A simple failure model fits the rotation data quite well.

\section{SUPPLEMENTARY MATERIAL}

The supplementary material for this article can be found at http://dx.doi.org/10.1017/jog.2016.104.

\section{ACKNOWLEDGEMENTS}

This research was partially supported by NASA grant NNX12AK29G to THD. DMH acknowledges support from NYU Abu Dhabi grant G1204 and NSF grant ARC130413.7. We thank Martin Truffer and an anonymous reviewer for their valuable comments.

\section{REFERENCES}

Amundson JM and 5 others (2010) Ice mélange dynamics and implications for terminus stability, Jakobshavn Isbræ, Greenland. J. Geophys. Res.-Earth Surf., 115, F01005 (doi: 10.1029/ 2009JF001405)

Benn DI, Hulton NR and Mottram RH (2007) 'Calving laws', 'sliding laws' and the stability of tidewater glaciers. Ann. Glaciol., 46(1), 123-130 (doi: 10.3189/172756407782871161)

Cook S and 7 others (2014) Modelling environmental influences on calving at Helheim Glacier in eastern Greenland. Cryosphere, 8 (3), 827-841 (doi: 10.5194/tc-8-827-2014)

Dixon TH and 7 others (2012) Emerging technology monitors ice-sea interface at outlet glaciers. Eos. Trans. Amer. Geophys. Union., 93(48), 497-498 (doi: 10.1029/2012EO480001)

Enderlin EM and Howat IM (2013) Submarine melt rate estimates for floating termini of Greenland outlet glaciers (2000-2010). J. Glaciol., 59(213), 67-75 (doi: 10.3189/2013JoG12J049)

Gorry PA (1990) General least-squares smoothing and differentiation by the convolution (Savitzky-Golay) method. Analytical Chem., 62(6), 570-573 (doi: 10.1021/ac00205a007)

Holland DM, Thomas RH, De Young B, Ribergaard $\mathrm{MH}$ and Lyberth B (2008) Acceleration of Jakobshavn Isbræ triggered by warm subsurface ocean waters. Nat. Geosci., 1(10), 659-664 (doi: 10.1038/ngeo316)

Howat IM and 5 others (2011) Mass balance of Greenland's three largest outlet glaciers. Geophys. Res. Lett., 38, L12501 (doi: 10.1029/2011GL047565) 
Joughin I, Abdalati W and Fahnestock M (2004) Large fluctuations in speed on Greenland's Jakobshavn Isbræ glacier. Nature, 432 (7017), 608-610 (doi: 10.1038/nature03130)

Joughin I and 7 others (2008) Continued evolution of Jakobshavn Isbræ following its rapid speedup. J. Geophys. Res.-Earth Surf., 113, F04006 (doi: 10.1029/2008JF001023)

Luckman A and 5 others (2015) Calving rates at tidewater glaciers vary strongly with ocean temperature. Nat. Commun. 6, (doi: 10.1038/ncomms9566)

Motyka RJ and 5 others (2011) Submarine melting of the 1985 Jakobshavn Isbræ floating tongue and the triggering of the current retreat. J. Geophys. Res.-Earth Surf., 116, F01007 (doi: 10.1029/2009JF001632)

Murray T and 10 others (2015a) Reverse glacier motion during iceberg calving and the cause of glacial earthquakes. Science, 349(6245), 305-308 (doi: 10.1126/science.aab0460)

Murray T and 9 others (2015b) Dynamics of glacier calving at the ungrounded margin of Helheim Glacier, southeast Greenland. J. Geophys. Res.-Earth Surf., 120(6), 964-982 (doi: 110.1002/ 2015JF003531)

Myers PG and Ribergaard MH (2013) Warming of the polar water layer in Disko Bay and potential impact on Jakobshavn Isbræ. J. Phys. Oceanogr., 43(12), 2629-2640 (doi: 10.1175/JPO-D-12-051.1)

Nick FM, Van der Veen CJ, Vieli A and Benn DI (2010) A physically based calving model applied to marine outlet glaciers and implications for the glacier dynamics. J. Glaciol., 56(199), 781-794 (doi: 10.3189/002214310794457344)

O'Leary M and Christoffersen P (2013) Calving on tidewater glaciers amplified by submarine frontal melting. Cryosphere, 7(1), 119128 (doi: 10.5194/tc-7-119-2013)

Otero J, Navarro FJ, Martin C, Cuadrado ML and Corcuera MI (2010) A three-dimensional calving model: numerical experiments on Johnsons Glacier, Livingston Island, Antarctica. J. Glaciol., 56 (196), 200-214 (doi: 10.3189/002214310791968539)
Peters IR and 6 others (2015) Dynamic jamming of iceberg-choked fjords. Geophys. Res. Lett., 42(4), 1122-1129 (doi: 10.1002/ 2014GL062715)

Rignot E and Kanagaratnam P (2006) Changes in the velocity structure of the Greenland Ice Sheet. Science, 311(5763), 986-990 (doi: 10.1126/science.1121381)

Rosenau R, Schwalbe E, Maas HG, Baessler M and Dietrich R (2013) Grounding line migration and high-resolution calving dynamics of Jakobshavn Isbræ, West Greenland. J. Geophys. Res.-Earth Surf., 118(2), 382-395 (doi: 10.1029/2012JF002515)

Strozzi T, Werner C, Wiesmann A and Wegmüller U (2012) Topography mapping with a portable real-aperture radar interferometer. IEEE Geosci. Remote Sens. Lett., 9(2), 277-281 (doi: 10.1109/LGRS.2011.2166751)

Truffer M and Motyka R (2016) Where glaciers meet water: subaqueous melt and its relevance to glaciers in various settings. Rev. Geophys., 54 (doi: 10.1002/2015RG000494)

Voight B (1988) A method for prediction of volcanic eruptions. Nature, 332(6160), 125-130 (doi: 10.1038/332125a0)

Voytenko D and 7 others (2015a) Multi-year observations of Brei amerkurjökull, a marine-terminating glacier in southeastern Iceland, using terrestrial radar interferometry. J. Glaciol., 61 (225), 42-54 (doi: 10.3189/2015JoG14J099)

Voytenko D and 5 others (2015b) Tidally-driven ice speed variation at Helheim Glacier, Greenland observed with Terrestrial Radar Interferometry. J. Glaciol., 61(226), 301-308 (doi: 10.3189/ 2015JoG14J173)

Voytenko D and 5 others (2015c) Observations of inertial currents in a lagoon in southeastern Iceland using terrestrial radar interferometry and automated iceberg tracking. Comput. Geosci., 82, 23-30 (doi: 10.1016/j.cageo.2015.05.012)

Werner C, Strozzi T, Wiesmann A and Wegmüller U (2008) GAMMA's portable radar interferometer. In Proceedings of the 13th FIG Symposium on Deformation Measurement Analysis, 1-10

MS received 1 April 2016 and accepted in revised form 2 August 2016; first published online 19 September 2016 